\title{
Aleitamento materno na experiência de mães de crianças traqueostomizadas e o uso da válvula Passy-Muir ${ }^{\circledR a}$
}

\author{
Breastfeeding based on the experience of mothers of tracheostomized children and the use of the Passy- \\ Muir ${ }^{\circledR}$ valve \\ Lactancia materna desde la experiencia de madres de niños traqueostomizados y uso de la válvula \\ Passy-Muir ${ }^{\circledR}$
}

Janaina Adriana da Cunha de Lima ${ }^{1,2}$ (1) Neusa Collet $^{3}$ (1) Maria Aparecida Baggio ${ }^{1}$ (1) Ana Maria de Almeida ${ }^{3,4}$ (D)

1. Universidade Estadual do Oeste do Paraná. Foz de Iguaçu, PR, Brasil.

2. Secretaria Municipal de Saúde de Foz do Iguaçu. Foz de Iguaçu, PR, Brasil.

3. Universidade Federal da Paraíba. João Pessoa, PB, Brasil.

4. Universidade de São Paulo, Escola de Enfermagem de Ribeirão Preto. Ribeirão Preto, SP, Brasil.
Autor correspondente: Ana Maria de Almeida. E-mail: amalmeid@eerp.usp.br.

Recebido em 06/08/2020.

Aprovado em 18/11/2020

DOI:https://doi.org/10.1590/2177-9465-EAN-2020-0290

\begin{abstract}
Resumo
Objetivo: compreender a experiência de mães de crianças traqueostomizadas, entre 0 e 24 meses de idade, que retomaram o aleitamento materno com o uso de válvula de deglutição Passy-Muir ${ }^{\oplus}$. Método: pesquisa descritiva, de natureza qualitativa, com 11 mães de crianças traqueostomizadas que adaptaram a válvula de deglutição Passy-Muir ${ }^{\oplus}$, acompanhadas em um centro de reabilitação e fonoaudiologia, mediante entrevistas semiestruturadas, nos meses de junho a agosto de 2017. A análise fo fundamentada nos pressupostos da análise de conteúdo temática. Resultados: na experiência das mães, após a traqueostomia da criança, o uso da válvula de deglutição Passy-Muir minimizou as dificuldades no aleitamento materno. Superado o processo de adaptação da válvula, foram percebidos seus benefícios. São descritos os sentimentos das mães nesse processo, suas expectativas quanto ao uso do dispositivo e o prazer e plenitude para a mulher no retorno do aleitamento materno. Conclusões e implicações para a prática: observaram-se segurança ao aleitar, menor produção de secreção, reduções no número de aspirações de vias áreas, melhora no padrão respiratório, vocalizações (balbucios e choro), melhora na qualidade do sono da criança. Novas pesquisas que abordem o aleitamento materno de crianças traqueostomizadas são necessárias para aprofundar conhecimentos nesta área.
\end{abstract}

Palavras-chave: Aleitamento Materno; Traqueostomia; Lactente; Cuidado da criança; Saúde Pública.

\begin{abstract}
Objective: To understand the experience of mothers of tracheostomized children between 0 and 24 months old, who resumed breastfeeding with the use of the Passy-Muir ${ }^{\circledast}$ deglutition valve. Method: A descriptive study with a qualitative approach and semistructured interviews conducted from June to August 2017 in which the participants were 11 mothers of tracheostomized children, by follow-up in a rehabilitation and logopedia center, which adapted the Passy-Muir ${ }^{\circledast}$ deglutition valve. The analysis was based on the assumptions of thematic content analysis. Results: the mothers' experience, after the child's tracheostomy, the use of the Passy-Muir ${ }^{\oplus}$ swallowing valve minimized the difficulties in breastfeeding. Once the valve adaptation process was overcome, its benefits were realized. The mothers' feelings in the process of adapting the valve are described, their expectations with the use of the valve and pleasure and fullness for the woman in the return of breastfeeding. Conclusions and implications for practice: Safety during breastfeeding, reduction in the production of secretions, and reductions in the number of airway aspirations were observed, noticing improvements in the respiratory pattern, in the vocalizations (mumbling and crying), and in the child's sleep quality. Further research is needed to address breastfeeding of tracheostomized children to deepen knowledge in this area.
\end{abstract}

Keywords: Breastfeeding; Tracheostomy; Infant; Child Care; Public Health.

\section{Resumen}

Objetivo: comprender la experiencia de las madres de niños traqueostomizados, entre 0 y 24 meses de edad, que reanudaron la lactancia materna con el uso de la válvula de deglución Passy-Muir ${ }^{\circledast}$. Método: estudio descriptivo, de carácter cualitativo, en el que participaron 11 madres de niños traqueostomizados, mediante seguimiento en un centro de rehabilitación y logopedia, que adaptó la válvula de deglución Passy-Muir ${ }^{\circledast}$, con entrevistas semiestructuradas, de junio a agosto de 2017. El análisis se basó en los presupuestos del análisis de contenido temático. Resultados: en la experiencia de las madres, después de la traqueotomía del niño, el uso de la válvula de deglución Passy-Muir minimizó las dificultades en la lactancia. Una vez superado el proceso de adaptación de la válvula, se hicieron realidad sus beneficios. Se describen los sentimientos de las madres en el proceso de adaptación de la válvula, sus expectativas con el uso de la válvula y el placer y plenitud para la mujer en el regreso de la lactancia. Conclusiones e implicaciones para la práctica: Se observó seguridad durante la lactancia, reducción de la producción de secreciones, reducciones diarias en el número de aspiraciones de las vías aéreas, advirtiéndose mejoras en el patrón respiratorio, vocalizaciones (balbuceo y llanto) y en la calidad del sueño del niño. Es necesita más investigación que aborde la lactancia materna de niños traqueostomizados, solidificando los conocimientos en esta área.

Palabras clave: Lactancia Materna; Traqueostomía; Lactante; Cuidados del Niño. Salud Pública. 


\section{INTRODUÇÃO}

O incremento no uso da traqueostomia em lactentes menores de um ano tem sido atribuído à maior sobrevida de recém-nascidos prematuros e daqueles que requerem ventilação prolongada, mas também pode estar associado a quadros de obstrução de via aérea. ${ }^{1}$

Embora seja necessária em alguns agravos à saúde, a traqueostomia leva a alterações no processo fisiológico de deglutição e, em lactentes, compromete o aleitamento materno. ${ }^{2}$ O cuidado constante com essas crianças e famílias implica resistência, compaixão e compreensão. Nesse sentido, criança e família requerem encaminhamento apropriado para serviços de apoio, pois têm demandas de cuidado singulares e complexas. . $^{3,4}$

Lactentes traqueostomizados são consideradas crianças com necessidades especiais de saúde (CRIANES). Estas carecem de atenção longitudinal e contínua da família, dos serviços e profissionais de saúde, envolvendo distintos agravos, que variam em complexidade e demandas de cuidados. ${ }^{5}$

Famílias de CRIANES são responsáveis por uma significativa gama de cuidados no domicílio, e, no caso de famílias de lactentes traqueostomizados, ainda enfrentam o desafio da manutenção do aleitamento materno, evitando o desmame precoce em decorrência dos transtornos de deglutição. ${ }^{6} \mathrm{O}$ desmame precoce interfere no desenvolvimento motor-oral, pois afeta as funções normais de mastigação, deglutição e postura da língua e lábios, além de interferir na ação muscular correta, que tem papel preponderante no crescimento facial e no desenvolvimento ósseo, possibilitando a instalação de má oclusão, respiração oral e alteração motora-oral. ${ }^{7}$

Portanto, a continuidade do aleitamento materno nessa população deve ser prioridade, pautada na perspectiva da tríade que envolve proteção, promoção e apoio, com o engajamento de profissionais de saúde para prevenir o desmame precoce. ${ }^{8}$ Nesse sentido, a fonoaudiologia contribui na reabilitação e minimiza as alterações de motricidade orofaciais, que podem surgir em decorrência da traqueostomia e da ausência do estímulo para sucção em seio materno. ${ }^{9}$

Lactentes que apresentam déficits orofaciais - incluindo aqueles que fazem uso de cânula de traqueostomia - manifestam dificuldades maiores em manter o aleitamento materno, e os distúrbios de deglutição e lactação têm impacto no seu bemestar e de suas famílias. Os pais vivenciam o estresse do cuidado da criança com necessidade especial, preocupações quanto a asfixia ou aspiração do leite, retardo no crescimento e isolamento social. ${ }^{10}$ Ressalta-se, no entanto, que a interrupção do aleitamento materno entre essas crianças pode ser revertida, desde que as mães sejam orientadas, apoiadas e acompanhadas, e aplicadas técnicas e cuidados especializados, incluindo a relactação e a lactação induzida.

O binômio mãe-lactente deve receber orientações, acompanhamento e apoio dos profissionais de saúde, os quais podem utilizar-se de instrumentos auxiliares na reabilitação. Em relação a lactentes traqueostomizados, salienta-se atenção especial ao dispositivo chamado válvula de deglutição Passy-
Muir ${ }^{\circledR}$, o qual é adaptado à cânula de traqueostomia e permite a continuidade do aleitamento materno sem intercorrências.

A válvula de deglutição Passy-Muir ${ }^{\circledR}$ é uma peça plástica, de formato cilíndrico, com interior oco, contendo uma membrana de silicone na sua porção anterior, que viabiliza a passagem unidirecional de ar (somente a entrada do ar inspirado). Quando acoplada na parte externa de uma cânula de traqueostomia ou em linha no circuito de um respirador, permite apenas o ingresso do ar inspirado através da cânula de traqueostomia, e redireciona o ar a ser exalado para as vias aéreas superiores, passando pela laringe (pregas vocais), faringe, boca e nariz. Ademais, possibilita a melhora na deglutição, no gerenciamento de secreções, no olfato e paladar e na emissão da voz em virtude do restabelecimento da pressão subglótica. ${ }^{11}$

Frente ao exposto, questionou-se: qual a experiência de mães de lactentes traqueostomizados na relactação com o uso da válvula Passy-Muir ${ }^{\circledR}$ ? Este estudo teve como objetivo compreender a experiência de mães de crianças traqueostomizadas, entre zero e 24 meses de idade, que retomaram o aleitamento materno mediante o uso de válvula de deglutição Passy-Muir ${ }^{\circledR}$.

\section{MÉTODO}

Estudo descritivo e exploratório, de abordagem qualitativa, desenvolvido entre junho e agosto de 2017, com participação de mães de crianças traqueostomizadas, que adaptaram a válvula de deglutição Passy-Muir ${ }^{\circledR}$ e retomaram ao aleitamento materno. Seguiram-se as recomendações do Consolidated Criteria for Reporting Qualitative Research (COREQ).

Foram incluídas 13 mães de crianças traqueostomizadas com idade entre zero e 24 meses, acompanhadas em um serviço especializado e de reabilitação, que retomaram ou estavam em processo de retomada do aleitamento materno com auxílio da válvula de deglutição Passy-Muir ${ }^{\circledR}$, e residiam em municípios da tríplice fronteira Brasil, Paraguai e Argentina. Dessas mães, duas foram excluídas: uma porque o filho foi a óbito e a outra que se mudou de cidade. Dessa forma, totalizou-se a participação de 11 mães.

Para a coleta de dados, a seleção das participantes foi por conveniência. Uma mestranda realizou as entrevistas, no serviço em questão, em encontros individuais, com duração média de 30 minutos, orientadas por um roteiro semiestruturado submetido a teste piloto e iniciado pela questão norteadora: Fale-me como foi sua experiência na retomada do aleitamento materno do(a) seu (sua) filho(a) com o uso da válvula de deglutição Passy-Muir ${ }^{\circledR}$.

O registro dos dados ocorreu por audiogravação, e as anotações de campo realizadas após cada entrevista. As transcrições das entrevistas retornaram às participantes para conferência. O fenômeno da saturação permitiu encerrar a coleta de dados.

Realizou-se a análise mediante a técnica de análise de conteúdo temática. ${ }^{12} \mathrm{Na}$ pré-análise, procedeu-se a uma leitura flutuante para a compreensão do conjunto de dados, seguida da leitura exaustiva para organização e tematização destes à luz do objetivo do estudo. Na exploração do material, os conteúdos de análise foram agregados e classificados para estabelecer as 
categorias temáticas. Na etapa de tratamento e interpretação dos resultados obtidos, foi possível colocar os dados em evidência, observar a concordância e a fundamentação das categorias temáticas sustentadas por literatura pertinente.

A pesquisa seguiu os preceitos éticos da Resolução n. 466/2012, do Conselho Nacional de Saúde, do Ministério da Saúde, com aprovação pelo Comitê de Ética em Pesquisa com Seres Humanos, da Universidade Estadual do Oeste do Paraná, Parecer n. ${ }^{\circ}$ 2.135.506. Para garantia do anonimato, as participantes foram identificadas pela letra $M$, relativa a mãe, seguida de numeração arábica conforme a ordem das entrevistas: M1, M2... M11.

\section{RESULTADOS}

As mães participantes deste estudo apresentavam faixa etária entre 31 e 44 anos, e a maioria tinha companheiro e ensino fundamental completo. Entre os lactentes, seis eram do sexo feminino e cinco do masculino, foram submetidos à traqueostomia no primeiro ano de vida, com exceção de três, e reiniciaram o aleitamento materno em até dois meses após o procedimento.

A análise dos dados substanciou a construção de três categorias temáticas: vivenciando a traqueostomia e os benefícios da válvula de deglutição Passy-Muir ${ }^{\circledR}$; o processo de adaptação com o uso válvula Passy-Muir ${ }^{\circledR}$ : sentimentos e expectativas; e retornando ao aleitamento materno: a plenitude e o prazer do ato.

\section{Vivenciando a traqueostomia e os benefícios da válvula de deglutição Passy-Muir ${ }^{\circledR}$}

Ao se defrontarem com os filhos submetidos à traqueostomia, as mães tiveram dificuldades em lidar com a condição das crianças, que choravam solicitando-lhes o peito e o colo. Conforme relatado, essa mãe não tinha suporte emocional e segurança para aleitar seu filho, agora traqueostomizado.

[...] eu chorava, eu não ficava com ele, meu marido que ficava. Eu me ausentava do quarto, porque ele queria mamar e não conseguia, aquela angústia toda. (M1)

Quadros de broncoaspiração são mais frequentes em criança traqueostomizada, pois a tosse reflexa é perdida, aumentando a vulnerabilidade a complicações. Em razão disso, as mães relataram medo de amamentar.

Quando tentei dar de mamar para ele, saiu tudo pela traqueo, ele teve quadro de broncoaspiração, desisti pelo medo. (M2)

[...] Eu até tentei, mas saía leite pela traqueo, e a fono que cuidou dela um tempinho lá em São Paulo não indicou amamentar por causa do risco de engasgar e broncoaspirar. (M9)

Nessa condição, a válvula de deglutição mostrou ser uma tecnologia que trouxe benefícios para o cuidado da criança traqueostomizada, conferiu segurança às mães, além de ser uma alternativa eficaz na retomada do processo de aleitamento materno. A própria criança conseguia perceber que o recurso lhe trazia benefício e conforto, demonstrando estado de relaxamento.

[...] Depois que ele colocou a válvula, ele já mamou. Quando ele via colocarmos a válvula, ele mamava e já relaxava ao ponto de dormir [...]. Trouxe conforto para ele. Vimos que aquilo já era um benefício. (M1)

O uso da válvula trouxe benefícios na rotina diária de cuidado às crianças traqueostomizadas. Particularmente às mães, permitiu maior tranquilidade, descanso e satisfação na interação com a criança. Elas conseguiam identificar e atender demandas fisiológicas de sono e fome, curtir sons de fala e realizar atividades de lazer sem preocupações. Consequentemente, proporcionou maior qualidade de vida às famílias.

[...] Foi muito bom. Não precisava aspirar muitas vezes [...]. Nossa vida mudou muito depois da válvula, fiquei menos cansada, menos nervosa, menos triste [...]. Foi melhor cuidar dele, não tinha mais catarro saindo na traqueo [...]. Ele dormia a noite toda [...] A válvula só ajudou, ele tossia menos, podia mamar de novo, e melhor de tudo foi ouvir ele chorar. (M4)

[...] Depois da válvula ele já começou a soltar sons, comecei a ouvir o choro dele. É emocionante ouvir a voz dele [...]. Depois da válvula ele já mamava no peito e deixava ele mais tranquilo [...]. Sei que ele não está sofrendo, tossindo e saindo secreção pela traqueo [...]. A qualidade de vida dele melhorou demais. (M2).

Mudou muito a vida dela, porque nos primeiros dias aspirava 15 a 20 vezes, logo que ela colocou a válvula diminuiu muito [...] a noite só acorda quando quer mamar, não aspira mais [... quando ela faz um movimento a gente escuta, ela grita, quando tem fome chora [...]. A gente fica mais descansada [...]. (M8)

Em suma, qualidade de vida para ela e para mim [...]já consegue mamar sem engasgar e até viajar é mais fácil porque não precisa aspirar no caminho [...] ela já faz barulhinhos, às vezes, na gargantinha e é uma forma de exercitar e creio que seja um benefício. (M1)

\section{O processo de adaptação com o uso da válvula Passy-Muir ${ }^{\circledR}$ : sentimentos e expectativas}

A proposição do uso da válvula foi recebida pelas mães com incredulidade, visto que era uma tecnologia que desconheciam, sem gerar expectativa de sucesso.

Nossa expectativa era singela, que ele pudesse pelo menos com a válvula dar mais proteção, porque a gente se preocupava muito. (M1) 
Então, como eu não conhecia, nem sabia nada a respeito, não gerei expectativa nenhuma, mas a princípio nós já percebemos que houve uma melhora. (M11)

Para algumas mães, o uso da válvula - alternativa que poderia facilitar o cuidado - gerou sentimentos de medo, ansiedade, angústia e insegurança durante o processo de adaptação.

Para mim foi sempre um medo, todo esse processo, claro que com todas as expectativas que pudesse melhorar [...] foi uma escolha difícil, isso nos trouxe angústia. (M1)

Confesso que foi difícil e assustador, porque o medo me assombrava, mesmo sabendo dos benefícios da válvula [...]. Nas primeiras mamadas eu fiquei um pouco ansiosa, mas fiquei mais segura quando pude ver que era seguro amamentar com a válvula. (M7).

Entretanto, logo no início do uso da válvula, as mães perceberam a evolução da criança, cujos benefícios observados superaram suas expectativas.

Eu achava que ele nunca ia sair da sonda [...] ele começou a mamar via oral [...] eu comecei a ver que ele estava desenvolvendo [...]. Correspondeu sim as minhas expectativas. (M3)

As expectativas foram atendidas com certeza, foi mais do que eu esperava. (M9)

Passaram, então, a expressar satisfação com o uso da válvula e reconhecer a melhora dos filhos, em vários aspectos, como na respiração, na amamentação e alimentação, na emissão de sons e fala.

[...] eu esperava que ela pudesse melhorar a respiração e foi além disso, ela conseguiu mamar no peito de novo e depois ela começou a comer e depois falar, eu escutar ela me chamar de mãe foi o dia mais emocionante para mim. (M9)

[...] foi muito mais do que eu esperava, eu tinha uma dor de ver minha filha sofrendo. (M6)

\section{Retornando ao aleitamento materno: a plenitude e o prazer do ato}

O uso da válvula Passy-Muir ${ }^{\oplus}$, como alternativa para superar as dificuldades do aleitamento materno, mostrou que essa tecnologia propiciou às mães recuperarem sua autoestima, $e$ as fizeram sentirem-se capazes de amamentar e cuidar do filho com segurança e tranquilidade.

Para mim foi uma sensação muito boa, amamentar meu filho foi uma sensação de plenitude [...]. Para mim foi crucial naquele momento, em termos emocionais, alimentar dele. (M1)

Poder dar de mamar, foi uma experiência que achei que não ia mais viver [...] foi muito especial dar de mamar para ele depois de tudo, [...] dar mamar a ele com a válvula foi muito mais tranquilo para os dois, eu por causa do medo dele engasgar e ele porque não ficava ofegante e não tossia mais. (M2)

O retorno ao aleitamento materno com o auxílio da válvula Passy-Muir ${ }^{\circledast}$ propiciou, às mães das crianças traqueostomizadas, recuperarem o sentimento de prazer durante $o$ ato de amamentar.

Dar de mamar para ela de novo, foi o mais importante de tudo para mim [...] foi o dia mais feliz, uma alegria tão grande que não posso explicar [...]. Quando ela mamava no meu peito eu não queria que acabasse, queria dar de mamar toda hora para colocar ela no colo e sentir ela mamando e rindo para mim. (M5)

Depois que ela colocou a válvula e mamou no peito eu fiquei olhando para ver se ia sair leite pela traqueo e não saiu. Eu chorei de alegria [...]. Isso mudou de um dia para o outro e só uma mãe que amamenta sabe o que é isso, foi maravilhoso para mim [...]. (M6)

Retomar ao aleitamento materno representou mais do que nutrir e ofertar alimento ao filho - envolveu sentimentos de esperança, consolo, gratidão a Deus, um recomeço. Família e profissionais estabeleceram vínculo durante o processo de adaptação da válvula, e o sucesso do aleitamento remeteu satisfação recíproca.

Poder amamentar foi o milagre que me trouxe a esperança. Eu até esquecia da hora quando eu amamentava, foi meu melhor presente, presente de Deus [...]. O dia que retirou a sonda de alimentação foi o dia mais feliz, chorou eu, meu marido, a enfermeira, a fonoaudióloga [...]. Ter uma experiência de sucesso depois de viver uma grande luta, foi consolador, foi um recomeço amamentá-la. (M7)

O apoio e o incentivo dos profissionais de saúde foram decisivos para o retorno ao aleitamento materno e a adaptação da criança e família com a válvula. As mães expressaram reconhecimento e importância das ações dos profissionais de saúde nesse processo.

Eu sempre tive o suporte da fonoaudióloga, não foi um atendimento de saúde pública, foi pessoal, porque construímos um vínculo. (M1)

A fonoaudióloga me instruiu muito bem, nos deixou ir para casa quando teve segurança que ele estava bem, ela o viu mamar, não desistiu de vê-lo sugar [...]. Fui muito bem assistida pela equipe de saúde [...] todos os 
profissionais me apoiaram. Sem apoio eu não conseguiria ir em frente. (M2)

Ela [criança] foi muito bem cuidada, foi muito importante porque eu não conseguiria sem vocês (profissionais). (M5)

\section{DISCUSSÃO}

Compreender a experiência de mães de crianças traqueostomizadas, durante a retomada do aleitamento materno por meio do uso da válvula de deglutição Passy-Muir ${ }^{\circledR}$, é fundamental para a estruturação e o desempenho de ações que se destinam ao atendimento dessas crianças. Este estudo apresenta experiências exitosas dessas mães na introdução de estratégias no cuidado de crianças traqueostomizadas e nas inovações que devem estar disponíveis.

Após a traqueostomia, as mães experimentaram dificuldades no aleitamento relacionadas ao fato de o leite materno sair pela cânula, o que provocava sentimento de insegurança frente à nova situação, implicando, ainda, a possibilidade de ocorrer broncoaspiração. As mães mostraram uma dualidade de sentimentos acerca da amamentação porque afirmavam ter leite materno, mas sentiam-se incapacitadas de amamentar seus filhos, uma vez que esse ato, concomitante à aspiração silente, colocava a criança em maior risco.

$O$ ato de amamentar a criança traqueostomizada a expõe a fatores de risco para aspiração respiratória, tendo em vista que apresenta disfagia, reflexo de tosse prejudicado ou ausente, reflexo de vômito diminuído ou ausente, disfunção motora da faringe, atraso no reflexo de deglutição, estase em recessos faríngeos (valécula e/ou seios piriformes) e alterações no mecanismo de fechamento faríngeo. ${ }^{10,13}$

No entanto, com a introdução da válvula, houve melhor interação mãe-filho, considerando que essa tecnologia proporcionou alívio de sintomas, visto que houve diminuição na produção de secreções e, consequentemente, reduziu as aspirações da traqueostomia. Destaca-se, ainda, a ocorrência de sono prolongado e a emissão de sons em decorrência dos benefícios do uso da válvula, que promove maior conforto para a criança e sua mãe. Com a expressão desses benefícios, considera-se que a válvula Passy- Muir ${ }^{\circledR}$ é uma tecnologia que favorece o controle da salivação, recuperação do olfato, do paladar, e o fluxo de ar é direcionado para vias aéreas superiores, favorecendo, também, a diminuição de secreção de em pessoas traqueostomizadas.

O uso da válvula Passy-Muir ${ }^{\circledR}$ permitiu que as mães retomassem o processo de aleitamento materno e promoveu benefícios como readaptação para a alimentação, e a melhora da deglutição e da comunicação. Acresce-se, ainda, melhora significativa na deglutição devido à pressão subglótica ser restaurada, e ao aumento positivo na sensibilização faríngea, reduzindo-se o risco de o alimento penetrar em vias aéreas inferiores. Além disso, favorece a ventilação e a oxigenação, auxilia no processo de desmame precoce da ventilação mecânica e aumenta as chances de decanulação do paciente traqueostomizado. ${ }^{2}$
Estudos apontam que o uso da válvula favorece a comunicação da pessoa traqueostomizada - fator importante para ela e sua família -, bem como exclui a necessidade de oclusão digital para a comunicação oral, reduz as secreções, previne riscos de infecções e melhora os sentidos do olfato e do paladar. ${ }^{14,15}$

Lactentes traqueostomizados e em uso da válvula PassyMuir $^{\circledR}$ fazem parte do grupo de Crianças com Necessidades Especiais de Saúde (CRIANES), por demandarem cuidados habituais modificados para além daqueles de outros na mesma faixa etária e serem dependentes de tecnologia. ${ }^{16}$ Destaca-se que, a fim de atender as necessidades de cuidado dessas crianças, as famílias devem ser preparadas para lidar com essa nova condição, bem como ter suporte na carga de cuidado que deverão oferecer à criança nessa condição. ${ }^{17}$

Portanto, o manejo da traquestomia é um cuidado complexo e não faz parte do repertório de cuidados de uma criança lactente, desencadeando múltiplos sentimentos nas mães. Dentre eles o medo foi o mais evidente. A falta de conhecimentos mais consistentes acerca da condição ou doença de seu filho torna a experiência desses pais uma condição angustiante e de sofrimento. Essa condição permanece, inclusive quando estão diante de alternativas que poderiam ter resultados positivos no cuidado, pelo medo do desconhecido, fato observado nas falas das mães quando introduziram o uso da válvula Passy-Muir ${ }^{\circledR}$. Tais sentimentos são reconhecidos em famílias com crianças adoecidas e, muitas vezes, as mães, por assumirem o papel de cuidadora principal, sentem-se inseguras, amedrontadas e impotentes no processo de cuidado. Portanto, quanto mais complexo o cuidado, maior a demanda de apoio das famílias. ${ }^{18}$

A insegurança decorre do medo do desconhecido. Tal sentimento pode perpassar o processo de adaptação no cuidado do filho, quando ocorrem transformações bruscas na rotina diária, no estado geral da criança, associado à necessidade de aprender novos procedimentos. A família precisa da parceria com os profissionais, e ter conhecimento sobre como acessar os serviços de saúde para garantir melhorias na saúde e bemestar do seu filho. ${ }^{19}$

Apesar de as mães demonstrarem um misto de incerteza e medo, elas conseguiram experimentar a nova tecnologia proposta para seus filhos e confiar no processo de evolução da condição clínica da criança. Com a possibilidade do uso da válvula de Passy-Muir ${ }^{\circledR}$ para o cuidado da criança traqueostomizada, renasceu, nessas mães, o sentimento de esperança.

Ao se apresentar, à família, a oportunidade de vivenciar uma reabilitação satisfatória ao estado de saúde da criança, e quando parte dessa evolução benéfica provém do uso de um recurso no processo de cuidar, sentimentos, anteriormente de impotência e fragilidade, são transformados em esperança e satisfação. Para isso, precisam receber orientação adequada, preparo emocional e treinamento para lidar com os dispositivos. Além disso, precisam de suporte familiar e acompanhamento profissional constante no domicílio. ${ }^{20}$

Quanto mais seguras e menos ansiosas na função materna e no manejo dos dispositivos necessários à criança, mais as 
mulheres se sentem confiantes em sua capacidade de interpretar e resolver as dificuldades da amamentação. Tal fato ocorre principalmente quando, em situações de agravos à saúde do filho, se Ihes apresenta uma alternativa eficaz para o controle do agravo e ainda permite a retomada do aleitamento materno..$^{21,22}$

Por se tratar de crianças que requerem uma assistência complexa e contínua, a família precisa incorporar novos saberes e práticas ao cotidiano. ${ }^{23} \mathrm{O}$ desejo de amamentar o filho as impulsiona a superar as barreiras. A expectativa de amamentar e estabelecer contato corpo a corpo maximizou o vínculo e a troca de afeto entre mãe e filho, suscitando sentimentos que conferiram prazer, satisfação, empoderamento, alegria, realização, autoconfiança, entre outros. Observou-se que, mesmo diante do medo do desconhecido, as mães desejaram auxiliar seus filhos. A satisfação delas, ao relatarem a experiência, foi expressa quando disseram que o uso da válvula Passy-Muir ${ }^{\circledR}$ superou suas expectativas e as permitiram enfrentar os desafios diante dos ciclos do tratamento de saúde do filho. Sentimentos semelhantes foram também apresentados em estudos nos quais as mães expressavam sofrimento pelo inesperado, tristeza pelo sofrimento do filho, mas, em contrapartida, manifestavam esperança e um desejo de lutar pela sua recuperação e de vê-lo melhorar. ${ }^{24}$

A possibilidade de amamentar levou as mães a superarem as dificuldades advindas da interrupção do aleitamento materno. Os benefícios do uso da válvula Passy-Muir ${ }^{\circledR}$ atuaram como estímulo à recuperação da sua autoestima e autoconfiança, expressando sentimento de que eram capazes de nutrir seus filhos, mesmo em condições adversas. A plenitude dessa experiência pôde ser apreendida nos relatos das mães ao retornarem ao aleitamento materno, representando um momento prazeroso, de satisfação, alegria, conforto, troca de afeto, carinho e amor.

As mães expressaram que o retorno ao aleitamento materno foi um desafio vencido no cuidado de seus filhos, confirmando que amamentar é mais do que nutrir a criança - é um processo de intensa ligação afetiva na relação mãe/filho que repercute no desenvolvimento emocional das mães, uma vez que o ato de aleitar proporciona prazer, contentamento, alívio, bem-estar. ${ }^{25}$

$\mathrm{O}$ apoio dos profissionais de saúde foi fundamental e imprescindível no processo de auxílio dessas mães e bebês na retomada do aleitamento materno. Salienta-se a importância do acompanhamento a essas famílias para reduzir o desmame precoce, sobretudo com ações educativas. ${ }^{26}$

Neste estudo, o apoio dos profissionais de saúde foi decisivo na mudança da qualidade de vida da criança, no seu desenvolvimento, e o suporte recebido imprescindível para o sucesso das ações de reabilitação propostas relativas ao cuidado dos lactentes traqueostomizados. Essa percepção das mães entrevistadas aponta a importância de práticas profissionais baseadas no respeito e na atenção, valorizando o diálogo como o fundamento para estimular a corresponsabilização e favorecer um cuidado compartilhado, voltado ao desenvolvimento integral das crianças e suas famílias. ${ }^{27}$

Como limitação, destaca-se o fato de essa investigação ter sido realizada com um número restrito de mães cujos filhos foram traqueostomizados na fase de lactação, o que impede a generalização dos resultados. No entanto, tais resultados podem ser utilizados na definição de políticas públicas, uma vez que, para o sucesso da técnica, as mães devem ter acesso à válvula de Passy-Muir®.

\section{CONCLUSÃO E IMPLICAÇÕES PARA A PRÁTICA}

Durante o processo de reabilitação, os benefícios observados apontaram para a retomada do aleitamento das 11 crianças deste estudo, segurança ao aleitar, menor produção de secreção, reduções diárias do número de aspirações de vias áreas, melhora no padrão respiratório, vocalizações (balbucios e choro), melhora na qualidade do sono da criança, readequação da deglutição e sucção, e a introdução de novos alimentos. As respostas ao uso da válvula Passy-Muir ${ }^{\circledR}$ foram benéficas e satisfatórias, e promoveram uma mudança significativa na qualidade de vida, nas atividades diárias da criança e de sua família.

Na prática assistencial às crianças em uso da válvula PassyMuir ${ }^{\circledast}$, o acompanhamento diário de uma equipe multidisciplinar é fundamental para que as mães superem os medos e a ansiedade no retorno ao aleitamento materno de crianças traqueostomizadas.

São necessárias novas pesquisas que abordem o desmame e a relactação de crianças traqueostomizadas, solidificando conhecimentos nesta área de atuação, uma vez que há um número limitado de estudos que correlacionem tais temas na literatura. Portanto, o estudo é relevante para a comunidade científica e a sociedade em geral, para profissionais da área da saúde, que atuam direta ou indiretamente à área de saúde materno-infantil.

\section{CONTRIBUIÇÕES DOS AUTORES}

Desenho do estudo. Janaina Adriana da Cunha de Lima. Maria Aparecida Baggio. Ana Maria de Almeida

Coleta ou produção dos dados. Janaina Adriana da Cunha de Lima. Ana Maria de Almeida.

Análise de dados. Janaina Adriana da Cunha de Lima. Maria Aparecida Baggio. Ana Maria de Almeida.

Interpretação dos resultados. Janaina Adriana da Cunha de Lima. Neusa Collet. Maria Aparecida Baggio. Ana Maria de Almeida.

Redação e revisão crítica do manuscrito. Janaina Adriana da Cunha de Lima. Neusa Collet. Maria Aparecida Baggio. Ana Maria de Almeida.

Aprovação da versão final do artigo. Janaina Adriana da Cunha de Lima. Neusa Collet. Maria Aparecida Baggio. Ana Maria de Almeida.

Responsabilidade por todos os aspectos do conteúdo e a integridade do artigo publicado. Janaina Adriana da Cunha de Lima. Neusa Collet. Maria Aparecida Baggio. Ana Maria de Almeida.

\section{EDITOR ASSOCIADO}

Eliane Tatsch Neves 


\section{REFERÊNCIAS}

1. Avelino MAG, Maunsell R, Valera FCP, Lubianca Neto JF, Schweiger C, Miura CS et al. First clinical consensus and national recommendations on tracheostomized children of the Brazilian Academy of Pediatric Otorhinolaryngology $(\mathrm{ABOPe})$ and Brazilian Society of Pediatrics (SBP). Rev Bras Otorrinolaringol. 2017;83(5):498-506. http://dx.doi. org/10.1016/j.bjorl.2017.06.002. PMid:28807655.

2. Medeiros GC, Sassi FC, Lirani-Silva C, Andrade CRF. Critérios para decanulação da traqueostomia: revisão de literatura. CoDAS. 2019;31(6):e20180228. http://dx.doi.org/10.1590/2317-1782/20192018228. PMid:31800881.

3. Joseph RA, Evitts P, Bayley EW, Tulenko C. Oral feeding outcome in infants with a tracheostomy. J Pediatr Nurs. 2017;33:70-5. http://dx.doi. org/10.1016/j.pedn.2016.12.012. PMid:27989396.

4. Sillers L, DeMauro S, Lioy J, Moran K. Feeding outcomes following infant tracheostomy. Pediatrics [Internet]. 2019; [citado 2020 out 7;144(2):480. Disponível em: https://pediatrics.aappublications.org/ content/144/2_MeetingAbstract/480

5. Ferreira FY, Xavier MC, Baldini PR, Ferreira LTL, Lima RAG, Okido ACC. Influence of health care practices in the burden of caregivers mothers. Rev Bras Enferm. 2020;73(Suppl 4):e20190154. http://dx.doi. org/10.1590/0034-7167-2019-0154. PMid:32696945.

6. Romley JA, Shah AK, Chung PJ, Elliott MN, Vestal KD, Schuster MA. Family-provided health care for children with special health care needs. Pediatrics. 2017;139(1):e20161287. http://dx.doi.org/10.1542/ peds.2016-1287. PMid:28028202.

7. Silva DP, Soares P, Macedo MV. Breastfeeding: causes and consequences of early weaning. RUC [Internet]. 2017; [citado 2020 maio 31]; 19(2):14657. Disponível em: http://ruc.unimontes.br/index.php/unicientifica/article/ view/489/454

8. Santos SP, Scheid MMA. Importância do aleitamento materno exclusivo nos primeiros seis meses de vida para a promoção da saúde da mãe e bebê. J Health Sci Inst [Internet]. 2019; [citado 2020 out 3];37(3):27680. Disponível em: https://www2.unip.br/presencial/comunicacao/ publicacoes/ics/edicoes/2019/03_jul-set/15V37_n3_2019_p276a280. pdf

9. Jesus LMR, Basso CSD, Castiglioni L, Monserrat AL, Arroyo MAS. Acompanhamento fonoaudiológico de crianças nascidas pré-termo: desempenho alimentar e neuropsicomotor. Rev CEFAC. 2020;22(4):e15119. http://dx.doi.org/10.1590/1982-0216/202022415119.

10. Van den Engel-Hoek L, Harding C, Van Gerven M, Cockerill H. Pediatric feeding and swallowing rehabilitation: an overview. J Pediatr Rehabil Med. 2017;10(2):95-105. http://dx.doi.org/10.3233/PRM-170435.

11. Zanata IL, Santos RS, Hirata GC. Tracheal decannulation protocol in patients affected by traumatic brain injury. Int Arch Otorhinolaryngol. 2014;18(2):108-14. http://dx.doi.org/10.1055/s-0033-1363467. PMid:25992074.

12. Minayo MCS. Pesquisa social: teoria, método e criatividade. 34. ed. Petrópolis: Vozes; 2015.

13. Bernardi AS, Berretin-Felix G, Silva-Arone MMA. Cânulas traqueais e disfagia orofaríngea: uma revisão integrativa da literatura. Rev Bras Cir Cabeca Pescoco [Internet]. 2015; [citado 2020 jun 5];44(4):187-93. Disponível em: http://www.sbccp.org.br/wp-content/uploads/2015/07/ Rev-SBCCP-44-4-Artigo-08.pdf

14. Sutt AL, Caruana LR, Dunster KR, Cornwell PL, Anstey CM, Fraser JF. Speaking valves in tracheostomised ICU patients weaning off mechanical ventilation: do they facilitate lung recruitmente? Crit Care. 2016;20(91):91. http://dx.doi.org/10.1186/s13054-016-1249-x. PMid:27038617.

15. Favero SR, Scheeren B, Barbosa L, Hoher JA, Cardoso MCAF. Clinic complications of dysphagia in patients admitted to an ICU. Disturbios Comum. 2017;29(4):654-62. http://dx.doi.org/10.23925/2176 2724.2017v29i4p654-662.

16. Marcon SS, Dias BC, Neves ET, Marcheti MA, Lima RAG. (In)visibility of children with special health needs and their families in primary care. Rev Bras Enferm. 2020;73(Suppl 4):e20190071. http://dx.doi. org/10.1590/0034-7167-2019-0071. PMid:32756747.

17. Page BF, Hinton L, Harrop E, Vincent C. The challenges of caring for children who require complex medical care at home: 'the go between for everyone is the parent and as the parent that's an awful lot of responsability'. Health Expect. 2020;23(5):1144. http://dx.doi.org/10.1111/ hex.13092. PMid:32542954.

18. Din TF, McGuire J, Booth J, Lytwynchuk A, Fagan JJ, Peer S. The assessment of quality of life in children with tracheostomies and their families in a low to middle income country (LMIC). Int J Pediatr Otorhinolaryngol. 2020;138:110319. http://dx.doi.org/10.1016/j. ijporl.2020.110319. PMid:32882602.

19. Minnaert J, Kenney MK, Ghandour R, Koplitz M, Silcott S. CSHCN with hearing difficulties: disparities in access and quality of care. Disabil Health J. 2020;13(1):100798. http://dx.doi.org/10.1016/j.dhjo.2019.04.002. PMid:31076227.

20. Kirchchoff BR, Diogo PF, Grigol AM, Mendes JS, Schultz LF. A vivência do cuidador familiar da criança em uso de traqueostomia no domicílio. Rev Soc Bras Enferm Ped. 2020 jan;20(1):6-12. http://dx.doi. org/10.31508/1676-3793202000002.

21. Viana MRP, Araújo LAN, Sales MCV, Magalhães JM. Vivência de mães de prematuros no método mãe canguru. Rev Pesqui Cuid Fundam Online. 2018;10(3):690-5. http://dx.doi.org/10.9789/2175-5361.2018. v10i3.690-695.

22. Vieira ES, Caldeira NT, Eugênio DS, Lucca MM, Silva IA. Breastfeeding self-efficacy and postpartum depression: a cohort study. Rev Lat Am Enfermagem. 2018;26(0):e3035. http://dx.doi.org/10.1590/15188345.2110.3035. PMid:30208158.

23. Okido ACC, Neves ET, Cavicchioli GN, Jantsch LB, Pereira FP, Lima RAG. Factors associated with family risk of children with special health care needs. Rev Esc Enferm USP. 2018;52(0):e03377. http://dx.doi. org/10.1590/s1980-220x2017048703377. PMid:30365673.

24. Cruz NM, Melo MCP, Silva LS, Costa e Silva SP.Vivência das mães na transição para o desmame natural. Arq Ciênc Saúde. 2017;24(3):19-24. http://dx.doi.org/10.17696/2318-3691.24.3.2017.583.

25. Corrêa AR, Andrade AC, Manzo BF, Couto DL, Duarte ED. The familycentered care practices in newborn unit nursing perspective. Esc Anna Nery.2015;19(4):629-64.http://dx.doi.org/10.5935/1414-8145.20150084.

26. Lima APE, Castral TC, Leal LP, Javorski M, Sette GCS, Scochi CGS et al. Exclusive breastfeeding of premature infants and reasons for discontinuation in the first month after hospital discharge. Rev Gaúcha Enferm. 2019;40:e20180406. http://dx.doi.org/10.1590/19831447.2019.20180406. PMid:31596342.

27. Mello DF, Wernet M, Veríssimo MLÓR, Tonete VLP. Nursing care in early childhood: contributions from intersubjective recognition. Rev Bras Enferm. 2017;70(2):446-50. http://dx.doi.org/10.1590/0034-71672016-0319. PMid:28403283.

\footnotetext{
${ }^{a}$ Artigo extraído da dissertação de mestrado Experiências de mães de crianças traqueostomizadas no uso da válvula Passy-Muirß e o retorno ao aleitamento materno, apresentada ao Programa de Pós-Graduação Saúde Pública em Região de Fronteira, da Universidade Estadual do Oeste do Paraná, Foz de Iguaçu, 2018, de autoria de Janaina Adriana da Cunha de Lima, sob a orientação de Ana Maria de Almeida.
} 